This item was submitted to Loughborough's Research Repository by the author.

Items in Figshare are protected by copyright, with all rights reserved, unless otherwise indicated.

\title{
Highway filter drains: precursors for maintenance management
}

\section{PLEASE CITE THE PUBLISHED VERSION}

http://dx.doi.org/10.1680/jinam.15.00005

\section{PUBLISHER}

(C) ICE publishing

\section{VERSION}

VoR (Version of Record)

\section{PUBLISHER STATEMENT}

This work is made available according to the conditions of the Creative Commons Attribution 4.0(CC BY 4.0) licence. Full details of this licence are available at: https://creativecommons.org/licenses/by/4.0/

\section{LICENCE}

CC BY 4.0

\section{REPOSITORY RECORD}

Stylianides, Theo, Matthew Frost, Paul Fleming, Ali El-Jaber, Mark Mageean, Andrew Huetson, and Tomasz Klimczak. 2015. "Highway Filter Drains: Precursors for Maintenance Management". Loughborough University. https://hdl.handle.net/2134/19482. 


\section{Highway filter drains: precursors for maintenance \\ management}

1 Theodoros Stylianides MEng

Research Engineer, Centre of Innovative and Collaborative Construction Engineering, Loughborough University, UK

2 Matthew W. Frost BEng, Dis, PhD, PgcHE, MPWI Academic Supervisor, School of Civil and Building Engineering, Loughborough University, Leicestershire, UK

3 Paul R. Fleming BEng, PhD, MCIHT

Academic Supervisor, School of Civil and Building Engineering, Loughborough University, Leicestershire, UK

Ali El-Jaber MBA (Finance), BSc(Hons.) Industrial Supervisor, Asset Management Manager, Connect Roads, Balfour Beatty Investments, UK
5 Mark Mageean BEng (Hons) FCIHT

Industrial Supervisor, Regional Operations Director, Connect Roads, Balfour Beatty Investments, UK

6 Andrew Huetson

Industrial Supervisor, Business Manager, Connect Roads, Balfour Beatty Investments, UK

7 Tomasz Klimczak

Industrial Supervisor, Technical Manager, Pavement Testing Services, Adlington, UK
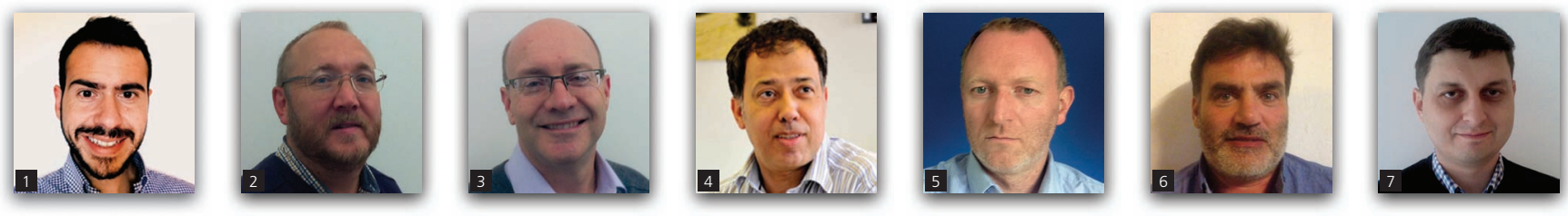

This paper conceptualises and presents a number of asset management building blocks required to establish holistic management for highway filter drains in the UK roads network. This is accomplished by evaluating current maintenance and management thinking and by identifying how existing strategies are lacking and potentially unsustainable. A condition assessment regime is hence described, tied to a measure of filter drain level of service (drainability) and an asset-specific ageing/renewal model that adopts six discreet condition bands is proposed. For this model to hold true, the Markov process is assumed to represent cumulative damage in a network. Drawing from relevant asset management concepts, a decision support tool to inform and optimise managerial decisions in respect to maintenance planning and resources allocation is also described.

\section{Notation}

$a_{0} \quad$ base condition vector

$a_{t} \quad$ condition vector in analysis year $t$

$e_{\mathrm{fr}} \quad$ void ratio of as-new aggregate

$G_{\text {sf }}, G_{\mathrm{SA}}$ specific gravity of fouling and filter aggregate materials, respectively

$i, j \quad$ index for asset state

$k_{\mathrm{v}} \quad$ hydraulic conductivity

$L \quad$ asset life selected for analysis in Markov transition probability matrix

$M_{\mathrm{F}}, M_{\mathrm{A}}$ mass of fouling and filter aggregate materials, respectively

$n$ number of condition bands used in Markov transition probability matrix

$P \quad$ transition probability matrix

$P_{000.63 m m}$ percentage by mass passing the 0.063-mm-size sieve

$P_{\% 10 m m}$ percentage by mass passing the $10-\mathrm{mm}$-size sieve (fouling material)

$P_{\mathrm{DF}} \quad$ percentage drain fouling $p_{i, j} \quad$ transition probability from state $i$ to state $j$

$R_{\mathrm{F}-\mathrm{A}} \quad$ foulant to aggregate ratio

$R_{\mathrm{FV}} \quad$ free voids ratio

$V_{\mathrm{F}}, V_{\mathrm{A}} \quad$ volume of fouling and filter materials aggregate, respectively

$V_{\mathrm{VFRA}} \quad$ volume of voids in as-new aggregate

\section{Introduction}

Highway filter drains (HFDs) are aggregate-filled trenches fitted with a porous carrier pipe at the base used in the UK to drain significant lengths of the highway network. The granular material used, which is typically (but not restrictively) exposed at the surface of the trench, allows for efficient removal of pavement runoff due to its high porosity. It also enables the removal of subsurface water from the pavement foundation and structural layers. HFDs thus act as a combined drainage system. Such systems can be advantageously employed in cutting situations requiring significant groundwater removal, and because of their large hydraulic capacities, they can also safely remove surface 
water during heavy storms. Filter drains are constructed in verges and/or central reserves adjacent to the low edges of pavements enabling surface water to run off the pavement directly onto the trench and then permeate through the aggregate backfill to the pipe at the base of the drain (Highways Agency, 1998).

HFDs have a finite operational life because of the reduction of free voids space of the filter material as road detritus and other fines enter the drainage trench, restricting the free flow of water. Currently, there are no formal systems in place to manage or monitor the performance of the drains and maintenance is typically carried out as reactive work (find and fix) or emergency work. Planned maintenance that is undertaken normally tends to be based on empirical evidence or experience in a given network with little formal monitoring or long-term planning of investments.

The paradigm of management of highway assets has moved over the years towards proactive philosophies, sustainable thinking and rational economic justification of all maintenance and rehabilitation work; this is evident in the various publications addressing the need for efficient highway asset management (AM) presented in recent years (DFT, 2014; BSI, 2014; Taggart et al., 2014; UK Roads Board, 2005; UKRLG, 2013). These documents typically offer a high-level overview of the fundamental concepts to be developed and adopted by local authorities and network operators to meet the minimum requirements of AM systems. They thus usually introduce strategic frameworks to address what should be done with existing groups of highway assets. Although being mainly pavement focused or strategy oriented, they lack the context that allows managers and road operators to establish how these frameworks could be put in practice for drainage systems and particularly HFDs.

This paper aims to establish precursors for a systematised evaluation and comprehensive management of HFDs. Existing HFD degradation characteristics and maintenance strategies are thus evaluated, and concepts of maintenance and asset management (MM, AM), condition assessment and deterioration modelling are summarised and mapped to the drainage system in question. To support the development of a maintenance and management platform for this particular type of drainage asset, a set of management building blocks and a number of HFD ad hoc variables to be embedded within such a platform are hence defined and proposed.

The organisation of the paper is as follows: The next section presents existing maintenance thinking and defines by evaluating HFD maintenance practices the need for a better management approach. In the third section, AM concepts are briefly introduced in an effort to identify those elements that are required to form a suitable filter drain management platform. This enables the writers to conceptualise in the fourth section a condition assessment regime mapped to an anticipated level of performance. Finally, a deterioration modelling approach to be embedded within a decision support tool (DST) is described in the final section.

\section{HFD deterioration and maintenance thinking: the need for a better approach}

There is nothing novel about introducing AM thinking to HFD; the principles adopted (on a strategic level at the least) all over the highway sector for individual asset categories in the last four decades could in principle be applied to HFD management. With vast lengths of filter drains installed in the UK highways network, there will soon be a backlog of maintenance work and a requirement to invest in an intelligent and rational HFD-specific management system (MS). If the climatic changes and their effect on drainage assets are also taken into account (such systems will eventually be further stressed and there will be a requirement for increased runoff removal efficiency), it can be proposed that the development of a structured methodology to support maintenance decision making should be prioritised sooner rather than later.

To move focus from an approach that solely factorises short-term rehabilitation needs to a methodology that satisfies both the shortterm integrity and long-term sustainability of HFD, the current HFD service and deterioration understanding and the existing maintenance and rehabilitation frameworks are evaluated here. How the current (maintenance) thinking translates to a need for a better management approach is thus identified before a more structured representation of the missing HFD AM elements can be proposed through this work.

\section{Current HFD deterioration understanding}

Current UK design guides suggest that HFDs should achieve an operational life of approximately 10 years. The filter material is then expected to require replacement or recycling, and this is often included in maintenance plans. However, during filter drain field evaluations (Farrar, 1994; Farrar and Samuel, 1989; Samuel and Farrar, 1988), acceptable performance of drains have been observed after 20 years of operation with minimal or no maintenance undertaken. These reports have also shown that there can be a differentiation between the service life of type A and type B (types A and B define different gradings of filter material with type A being finer) backfilled trenches and an implied correlation between filter specifications and modes of failure. Type A is reported to be prone to collecting road detritus at or near the surface of the drainage trench. Some of the key findings of these studies indicate poor construction standards and use of material that does not meet specification criteria, hence implying that the asset's longevity may have been affected by poor construction quality. To fully capture a more accurate representation of HFD (average) service lives (and taking into account the aforementioned work), there is a need to further evaluate deteriorated drains and collect appropriate condition data.

Since these reports have been published, there has not been any other significant output (academic or industrial) whatsoever regarding the asset's performance and/or its degradation characteristics and, more importantly, how to address key maintenance planning issues. 
One exception to this, Rowlands and Ellis's (2007) work, addresses in situ recycling as a means of introducing a level of sustainability and control over HFD maintenance operations. The authors focus on a novel rehabilitation approach and offer an overview of waste management issues during maintenance work but do not introduce a theoretical framework to support intervention time frames and holistic management; they instead adopt the existing empirical HFD service life projections often employed in the sector.

In the meantime, Highways England (HE) has brought forward a policy of non-recommendation for use of HFD in new projects, and this drainage option remains in UK standards for maintenance and rehabilitation operations. There are a number of reasons for this that may be attributed to design limitations (stone scattering as a safety hazard, cost of suitably graded stone in some regions), lack of engineered assessment methodologies to evaluate performance drop (malfunction of drainage system may go unnoticed) and the requirement for regular maintenance and replacement of filter stone at end of service life. These should presumably reinforce the case of introducing a holistic MS to deal with HFD in the roads network.

\section{Defining maintenance and maintenance strategies}

In terms of maintenance thinking, routine, corrective, preventive, predictive, proactive, and reactive strategies are terms often adopted in the industry to deal with the various approaches used for management of the physical assets in the UK's highways. These are often interrelated; the most obvious distinction between the strategies is based on whether failure has occurred even though the definition of a failed state for a number of assets remains in many instances blurred (Uddin et al., 2013). It is thus easier (in terms of HFD management) to define maintenance using the terms proactive (prevent impending loss of acceptable drainage capacity and employ evaluation methods factorising condition or time) and reactive (run asset to failure and treat once drainage capacity is below acceptable thresholds, or a firefighting approach to maintenance (Swanson, 2001)). This of course requires a clear definition of the asset's functions, how these are impaired, what the relevant failure modes are, what causes them and how these can be detected, and lastly what the impact on the pavement system and road user will be.

For HFD maintenance, interventions are still largely regarded as necessary repair work. While the importance of drainage has been highlighted as a main factor affecting long-term pavement performance (Cedergren, 1974; Hudson, 1968; Mallic and El-Korchi, 2013; Robinson et al., 1998) and driver safety (Johnson and Chang, 1984), there has not been a targeted effort to introduce the means for holistic drainage management or decision-aid toolkits. Drainage is not central in pavement management systems (PMSs), and engineered assessment techniques and rational maintenance strategies are in many cases omitted or considered to a lesser extent (Haas et al., 1994; Robinson et al., 1998). HFD are often in service until they fail in removing surface runoff from the pavement in an efficient manner, and there is still no way to predict or even classify functional failures. The alternative maintenance thinking (the first being in essence reactive) suggests implementing a time-based approach. Under this strategy, HFD maintenance and rehabilitation may be specified in a cyclic fashion (annual or biannual maintenance cycles or hard-time replacement at the end of the HFD design life) - see Figure 1.

Time-based maintenance (TBM) policies are usually derived on the premise of a bathtub curve (Klutke et al., 2003), which maps the gradual deterioration of the asset to increasing failure rates as cause and effect after a given service period (Ahmad and Kamaruddin, 2012; Yam et al., 2001). Under this scenario, maintenance, renewal and rehabilitation $(M, R \& R)$ tasks are scheduled at predetermined time or service intervals, and in general terms, time between successive interventions remains constant for asset categories with

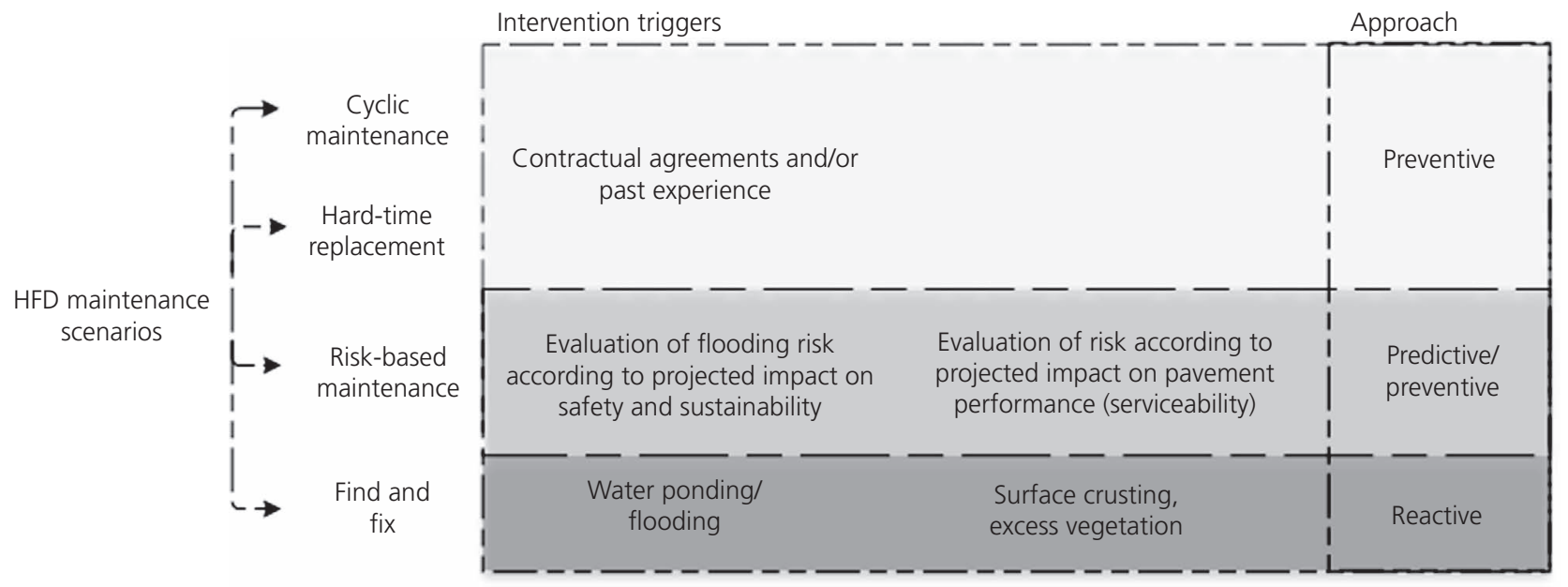

Figure 1. Current maintenance thinking, intervention triggers and philosophies 
similar design characteristics. If these assets do not present a narrow failure distribution pattern that can be accurately predicted (Swanson, 2001), two scenarios will subsequently be presented: one, only part of the useful life of the asset will be utilised between interventions, or two, failures will not be addressed in a timely manner. Both scenarios will eventually incur additional costs to road operators and users by imposing unnecessary treatments or unexpected failures, with the latter imposing additionally a critical safety hazard. Safety implications (in terms of limiting water accumulation on the pavement surface and all relevant hazards) thus commonly dominate the planning process of maintenance operations under a reactive philosophy.

This suggests the reassessment of the existing HFD management thinking in order to establish how effectively maintenance interventions are planned and undertaken. From the studies and field evaluations reported above, it can be concluded that the degradation characteristics of in service HFD will not (restrictively) be a function of operational life (or the current definition of HFD service life is misleading). Takata et al. (2004) suggest that rates of deterioration for various asset types depend on operational and environmental conditions, and clearly, for filter drains, construction quality and maintenance history will also have a role to play. Initial projections of design lives of 10 years seem to be an underestimate, but functional failures that are related to the surface water removal capacity can appear within this period and will require attention. Under a TBM approach, M,R\&R actions that are usually trench scarifying or vegetation control can be specified on annual/biannual cycles; aggregate replacement (HFD reconstruction) is due after 5 or 10 years of service life.

\section{A brief overview of highway infrastructure asset management (IAMS) and a number of drainage management fundamentals}

Having established an overview of the current HFD maintenance thinking, the need to redefine the existing HFD-specific management model is proposed; an overview of a number of IAMS fundamentals is thus presented as the topic of AM is evaluated adopting topdown (British Standards, good-practise guides, design manuals) and bottom-up (drainage condition assessment literature) approaches. Some key features of PMSs are described, founded upon generic AM thinking, and a number of elements that can be transferred to a filter drain management framework are thus identified. This section examines how the combination of existing AM know-how and tactical drainage-explicit assessment literature may lack some of the key fundamental prerequisites required to move towards holistic management of this particular type of drainage asset.

\section{The building blocks of AM - a top-down approach}

A generic framework that describes the requirements for holistic AM is proposed by Hassanain et al. (2003) using five key operations, which are

- identify assets,

- identify performance requirements,
- assess performance,

- plan maintenance,

- manage maintenance operations.

Similarly defined AM frameworks can be found in the literature; in Wittwer et al. (2002), condition assessment and trade-off analysis are included in the basic cycle of an AM framework (physical condition and asset performance as descriptors of the effectiveness of service delivery are often used hand in hand), whereas Dornan (2002) goes into further detail in asset renewal/replacement analysis methods (life-cycle cost, cost-effectiveness analysis or equivalent annual cost) and asset disposal policies. In practice, even though different definitions can be found, an AMS is the combination of engineering and business practices to support decision making at the strategic, network and project levels; in other words, it is a way of doing business by adopting the right procedures to achieve results cost effectively with the limitation of sparse resources (Cambridge Systematics et al., 2006; Godau, 1999).

Individual asset-specific MSs like PMSs were founded on this theoretical framework focusing on the key objective of costeffective infrastructure maintenance and operation. PMSs are essentially the collection of all tools, technologies and processes that help managers make better decisions and manage their pavements more effectively. Their implementation since the late 1960s (Markow, 1995) came as a response to the shift from design-and-build operations to the repair-and-maintain mode. At this point, PMSs are abundantly available for use but other highway-related MSs have emerged to deal with bridges (bridge management systems), safety (safety management systems) and in-house maintenance operations (maintenance management systems) (Li and Sinha, 2004).

While all these systems address different asset categories and functions within the highway network, they integrate at their cores the same systems thinking and management principles (this work emphasises how drainage management has not yet embedded such an approach). They are fundamentally information driven, heavily dependent on databases (inventory, condition, historic maintenance, budgets, M,R\&R options/impacts/costs) and employ a particular type of analysis that allows asset managers to fine-tune interventions, optimise asset life cycles and carry out investment decisions for preservation, expansion and operation of any given network. The data required for a MS are produced by monitoring and inventory activities, while modelling provides the tools for planning, trade-off analysis, ranking, and optimisation (Li et al., 1997). For PMS, pavement performance models adopt either deterministic (Abaza, 2004; Abaza et al., 2001; Wong et al., 2003) or probabilistic (Abaza et al., 2004; Golabi et al., 1982; Li et al., 1997) approaches, and DSTs that integrate prioritisation or optimisation models.

The recently published Highways Infrastructure Asset Management Guide (UKRLG, 2013) complements the ISO 55000 (BSI, 2014) series on the topic of AM in the UK. The latter supersedes the previous AM standards (PAS, 2008) and now offers an overview of 
$\mathrm{AM}$, the requirements for an $\mathrm{AM}$ system and the guidelines for the application of ISO 55001. The ISO is a high-level strategic guide that introduces systems thinking and AM organisational precursors in a business-oriented manifesto that aims to standardise AM. A tactically oriented document, the UKRLG (2013) guide focuses on physical assets in highway networks, offering 14 recommendations to achieve an appropriate level of benefit from AM. These recommendations deal with various themes, including life cycle plans, performance management and monitoring, risk management and AM policy and strategy. The drainage-specific guidance document HMEP (2012) in turn focuses on establishing a costeffective approach to managing drainage assets, based on building drainage-specific databases (inventory, condition, maintenance intervals, frequency of failures, maintenance requirements, etc.) and using this information to apply relevant AM principles. The guide highlights various strategic requirements to be developed and offers a number of concise recommendations (i.e. the requirement to address the causes of problems as opposed to symptoms and the requirement to use asset data to focus, support and inform maintenance activities mapped to overall AM objectives). It also proposes the adoption of proactive and prioritised programmes and the need to support these using asset condition data.

All these documents describe a 'high-level' framework to be developed but do not go into detail with regard to the inventory data to be collected, the condition metrics to be established, the performance indicators to be introduced or, lastly, the deterioration and maintenance optimisation models to be built. For a number of asset types (i.e. pavements) a wide spectrum of these parameters can be found in relevant AM or asset assessment literature. This will not hold true when drainage systems are to be evaluated; this simply highlights that a top-down approach through the available strategic and tactical publications will enable road administrators, operators and local councils to establish the required AM framework (or the AM know-how) but eventually the practical end of such a system will need to be addressed: what kind of data are to be collected, how are these to be used and in what sense will the outputs reinforce the case of AM and be of true value.

\section{Managing drainage assets: the bottom-up option}

At the lowest AM tier, with a more operational focused document, Spink et al. (2014) approach the issue of managing drainage assets in the latest CIRIA publication that addresses some of the questions raised in the previous sections. The guide thus includes elements for inventory and condition data collection and evaluation and a proposed performance assessment regime. Being primarily focused on condition appraisal, the publication defines structural and service conditions as the two main parameters to be extracted through drainage condition surveys building upon visual evaluation. Five discreet condition bands in a one-fits-all assessment approach are included in the text.

While the proposed bands could be used to characterise individual HFD sections, the methodology embedded in the assessment procedure to reach them is rather generic. The deterioration characteristics of HFD are not considered, and the boundaries proposed to establish the discreet condition states are largely empirical; these are derived by rating the asset employing visual means rather than identifying and measuring the type and extent of the severity of fouling in an evaluated section. In fact, no framework for intrusive (or other non-destructive) evaluation is described in detail and thus a large portion of the information required to assess HFD is omitted (severity of sedimentation and extent within filter media tied to HFD failure modes). The condition evaluation adopting this approach would retrospectively address only one of the (two) HFD failure modes; that would be the reduction of surface runoff removal capacity (functional failure) due to surface crusting (failure mode), and thus, the duality of this particular drainage system is ignored.

Performance assessment in the guide is similarly based on visual surveys, but these can take place only when water can be found within the system (making assessments impossible during dry periods) or the combination of the two condition components identified (structural and service condition as a proxy for performance). The former approach is largely reactive as it suggests addressing the symptoms of HFD deterioration (reduced performance) as opposed to what causes this (sedimentation and reduced void space in trench) but can potentially allow the identification of flooding hotspots and be of value at the network level. The latter is again based only on evaluating the exposed filter media and thus is bound to provide limited information on the overall drainability of a section.

In simple terms, the major issue with this assessment approach is that the essence of fouling, its extent within the HFD trench and how that correlates to the drainability of a section are not explicitly or adequately considered in determining maintenance and renovation strategies. Since the sedimentation levels are not quantified, the actual capacity of the drain to remove water from the pavement system is not considered. In truth, a visual inspection-based condition-rating index can offer a quick evaluation methodology at the network level, it is though based on rating (rather than measuring) physical characteristics of the aggregate fill and bound to ignore some of the relevant information required to draw conclusive remarks for the current condition of the asset.

Also of interest is how local authorities currently approach the matter of managing drainage assets; adopting the UKRLG (2013) code of practice, condition standards are proposed at three domains here: safety, serviceability and sustainability. Maintenance plans produced by councils, which can be considered the tactical and/or operational side of the AM systems in place, suggest managing drainage assets adopting a risk or a fire-fighting approach (Bournemouth Borough Council, 2008; Middlesbrough Council, 2006; Suffolk County Council, 2008; Walsall Council, 2012).

Such plans will generally include guidelines for managing all relevant transportation assets; in the cases of carriageways, footways or cycle routes (and drawing from the Well Maintained Highways 
code of practice), a number of condition parameters (deflection, surface defects, skidding resistance, weed growth, slipperiness, etc.) are to be measured and mapped against the core objectives of a highway maintenance regime for each domain. Drainage condition standards lack any such parameters or metrics. Instead, the three core objectives are streamlined against flooding risk, which is in principle a measure of performance rather than physical condition. This can be a facilitator of a reactive maintenance philosophy or of a preventive one that is primarily based on subjective indicators due to the lack of other condition metrics.

It is evident that our current thinking is lacking; in terms of planning, management of investments and understanding the factors that drive the deterioration of HFD, our strategies are largely underdeveloped and are primarily based on empirical methods (and thus tend to be reactive). This is due to a combination of factors; drainage has been neglected in the past, efforts to implement assessment techniques only partially addressed AM requirements, strategic guides offer fundamental (strategic) concepts lacking the 'engineering-end' of the management equation and empirical and/or time-based approaches offer limited opportunities to evaluate the physical condition of an asset and thus to collect relevant and specific HFD data.

\section{(Re)paving the way for an HFD-MM system}

\section{Where top-down meets bottom-up}

Maintenance thinking has evolved in recent decades to meet the requirements for greater dependence on business and engineering principles, use of benefits and costs through what-if and life-cycle scenarios, rationalisation (and thus lesser dependence on generic standards) and, lastly, accountability of data and of performance projections. The sector's thinking has long moved from considering maintenance as necessary repair work, and the definition of Robinson et al. (1998) of 'maintenance as a management issue concerned with delivering a defined quality of service, activities and procedures, timing of interventions and resources of people and materials' conclusively illustrates the fact.

The adoption of AM principles in the highways sector has been briefly described in the previous section. By identifying the gap between introducing the AM know-how and embedding the engineering prerequisites for this to be of value, the development of a set of HFD management building blocks is proposed. Looking to formulate an HFD-specific AM subsystem, the particular characteristics of the asset are to be considered and evaluated in a framework that will be in line with other existing asset-specific AM systems and thus should include

a geo (or network)-referenced inventory database of HFD,

- condition data classifying deficiencies accountable for drainability levels,

- maintenance history,

network-level HFD condition distributions,

- ageing/deterioration modelling and estimation of remaining service life,
- intervention analysis and network level program costs mapped to projected condition,

- optimisation of investments,

- project level analysis and tactical overview of maintenance requirements for candidate projects.

The eight elements described here address the five key operations defined by Hassanain et al. (2003), and will in principle allow asset managers to approach the task of managing HFD employing a rational set of decision-aid tools. Some of these themes look trivial and a fair amount of relevant information can be found scattered in the existing literature (e.g. drainage inventory and/or condition data collection in Spink et al., 2014) potentially offering some indications in respect to how to advance the framework. Focusing on HFD-specific elements that deal with quantifying the severity and extent of what drives the drop in serviceability levels and reflect the engineering orientation of the system, a suitable platform that deals with the ad hoc asset design features, how these change during service life and what impact this has on drainage capacity, needs to be defined.

Further expanding the proposed HFD management framework, the need to develop and introduce the methodology to support such elements as condition assessment, deterioration modelling, DSTs and optimisation of investments are identified. The following sections present the case of rational condition measuring that is considered the cornerstone of the aforementioned elements, and the tools that could eventually be developed using engineering assessment techniques.

\section{Making the case for rational condition evaluation} Assessing physical condition: measuring rather than rating Condition metrics have been used in various infrastructure asset groups; Sussman et al. (2001) suggest, for example, that in the case of railway condition evaluation, such an approach demonstrates potential for simplifying data interpretation, a fact that should in principle reinforce the case for rational condition measuring.

In pavement surveys, condition metrics quantify (severity) known characteristics of the various issues (distress) and map them to an anticipated level of service. This idea is well communicated and fairly understood. When reduced down to basics, condition indicators for any asset type evaluate how much of a particular type of severity is too much and how boundaries between satisfactory and non-satisfactory performances can be drawn.

\section{Coupling HFD and ballast condition evaluation}

The same principle can be considered when HFD are evaluated. To appreciate how the asset fails and what variables could potentially be introduced in a condition assessment system (CAS), HFD design requirements are initially presented. The aggregate fill used in HFD trenches is primarily based on the type A and type $\mathrm{B}$ aggregate envelopes that are expected to offer a range of in situ vertical permeability values. It is practically impossible and, in general terms, infeasible to directly measure how these 
values change within the effective operational life of an HFD section (or prior to construction). The parameter that can be studied while evaluating anticipated drainage capacity (surface or subsurface) and thus the level of service is the change in available void space within the filter as it reduces for in-service drains with fines infiltrating the trench.

A solution to the problem of classifying drainage capacity of large particle size aggregate materials with similar degradation properties has been developed in the railway industry. The methodologies established here aimed to form an inferred relationship between a fouling index (a quantification of undesirable material within a ballast section) and a drainability level (a quantitative estimation of a section's drainage capacity) for ballast evaluation. Selig and Waters (1994) introduced a simple assessment regime and based their condition evaluation on sampling, sieving and sorting of ballast material, suggesting the introduction of the fouling index. Building upon his work, a number of similar indices have been developed, some taking into account a mass-based quantification of foulants (Sussman et al., 2012), while others a volumetric representation of the fouling extent (Anbazhagan et al., 2012; Feldman and Nissen, 2002; Tenakoon et al., 2012). What is important to extract from these ballast-related condition assessment studies is the proposition that a combination of intrusive and non-intrusive condition assessment surveys that build upon the use of rational condition metrics (often correlating ground penetrating radar surveys with fouling levels (Al-Qadi et al., 2008; Anbazhagan et al., 2011; Leng and Al-Qadi, 2009)) can offer the data required for maintenance planning and efficient resource allocation.

\section{Evaluating asset distress and introducing condition metrics for HFD}

By evaluating the degraded characteristics of in-service drains, Stylianides et al. (2015) proposed the adoption of the fouling scales concept for the quantification of introduced material within an HFD trench. The condition metrics developed (see Equations $1 \mathrm{a}, 1 \mathrm{~b}, 1 \mathrm{c})$ and coupled to permeability trials suggest that an inferred relation between available void space and hydraulic performance can be extracted from site evaluations. This can in principle enable asset owners to quantify the extent and severity of the defection and thus to classify in-service performance of individual HFD sections.

1a. $\quad P_{\mathrm{DF}}=P_{\% 10 \mathrm{~mm}}+P_{\% 0.063 \mathrm{~mm}}$

1b. $R_{\mathrm{F}-\mathrm{A}}=\frac{V_{\mathrm{f}}}{V_{\mathrm{a}}}=\frac{M_{\mathrm{F}}}{M_{\mathrm{A}}} \times \frac{G_{\mathrm{SA}}}{G_{\mathrm{sf}}}$

$R_{\mathrm{FV}}=\frac{V_{\mathrm{VFRA}}-V_{\mathrm{F}}}{V_{\mathrm{VFRA}}}=\frac{e_{\mathrm{fr}} \frac{M_{\mathrm{A}}}{G_{\mathrm{A}}}-\frac{M_{\mathrm{F}}}{G_{\mathrm{f}}}}{e_{\mathrm{fr}} \frac{M_{\mathrm{A}}}{G_{\mathrm{A}}}}$
The fouling indices proposed in the work (fouling here is defined as the material found within a trench which is comprised by the particle size matrix below a 10-mm-size cut-off), are based on both mass and volumetric approaches and have been used to classify field samples collected from drains that have been in service for 10 years at the time. Figure 2 visualises depth-specific condition classification of two particular inservice HFD sections (namely, C and D) using particle size distribution (PSD) curves and two volumetric fouling scales $\left(R_{\mathrm{F}-\mathrm{A}}, R_{\mathrm{FV}}\right)$.

These indices, used to simulate the drop in vertical permeability values in laboratory tests conducted with type B aggregate material, present how the drop in levels of service of HFD could be estimated as a function of fouling levels ( $k_{\mathrm{v}}$ as a measure of drainability; see Figure 3). It has been proposed that for $R_{\mathrm{FV}}$ values below $0 \cdot 6$, measured $k_{\mathrm{v}}$ will be a function of the fouling material (foulant-dominated sample), and hence the aggregate fill would rate poorly in terms of drainage capacity.

\section{Ageing and deterioration characteristics, failure modes and functional failures}

By employing a physical condition classification regime, an engineered assessment system is introduced to quantify the extent and severity of fouling within an HFD section. The next step in formulating the HFD management framework is to use this particular assessment approach in formulating a better understanding of HFD degradation characteristics and a methodology to establish discreet condition bands for the drains. HFD failure modes are thus further evaluated in order to identify and introduce these bands (considering that available assessment criteria (Spink et al., 2014) underplay the duality of this particular drainage design) and to investigate how deterioration can be quantified and modelled.

\section{Loss of drainage performance and failure modes}

The research published on the evaluation of filter drains in the UK's highway network (see 'HFD deterioration and maintenance thinking: the need for a better approach' section) suggests two distinctive HFD failure modes. While limited, this literature (along with HFD empirical understanding and field evaluation conducted for this work) enables the writers to define HFD condition bands after depicting what each failure mode and functional failure represent.

The first mode, often correlated to the safety aspect, is presented with a near-surface degradation pattern. Sediments block the uppermost of the trench forming a cohesive crust that presents relatively low permeability values (failure cause). This will restrict the free flow of water through the surface of the HFD (loss of function/functional failure) and inevitably runoff will be redirected back to the carriageway, thus imposing a safety hazard for drivers. This moves the HFD condition in an undesirable state that requires timely consideration; the main body of the filter material may at this point remain in an 

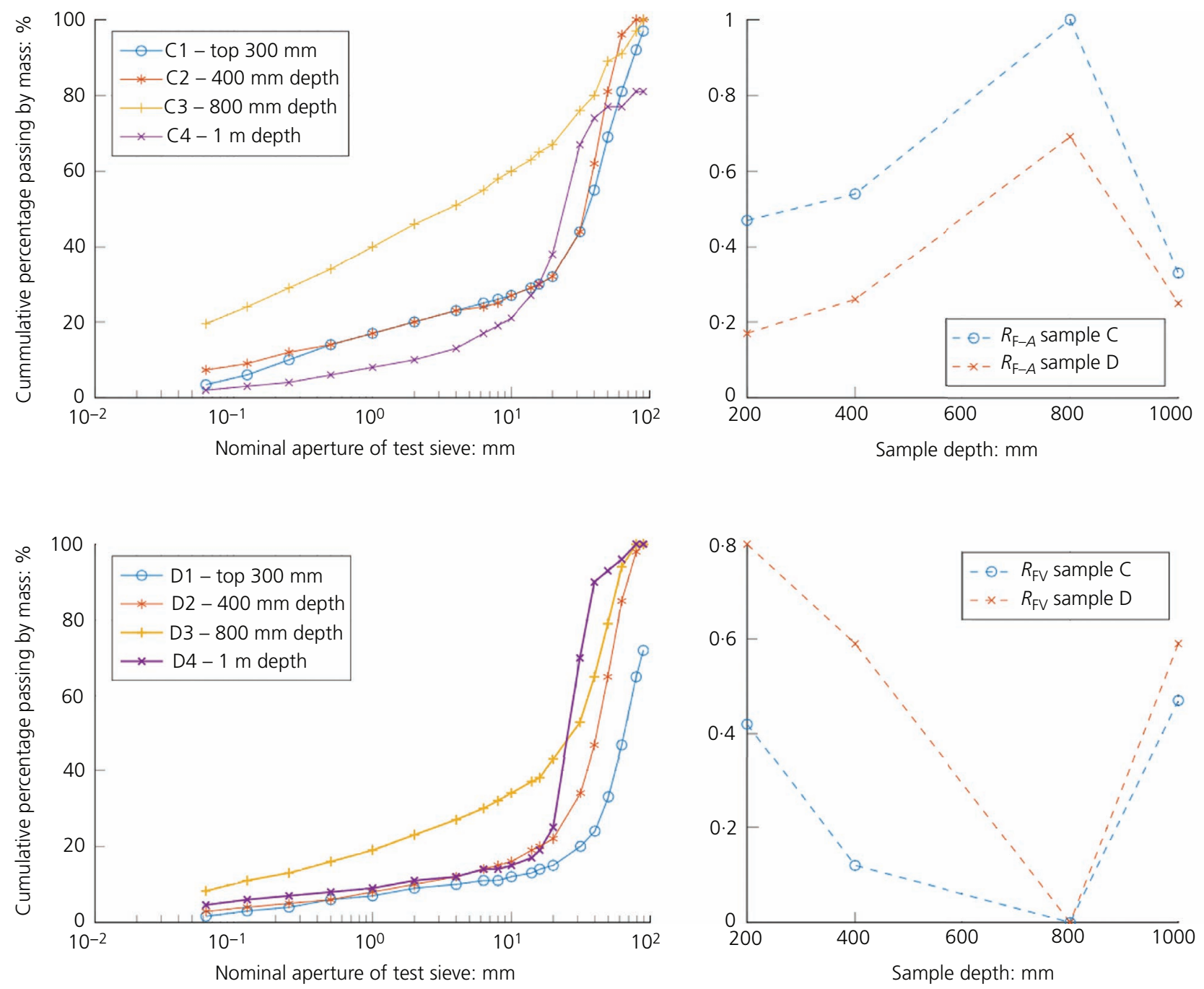

Figure 2. Fouling evaluation of field samples using PSD curves and fouling scales

acceptable state. Such failures have been reported to occur every 5-7 years (probability of occurrence), but more quantitative data are required to reinforce this projection. The second failure mode manifests with a bottom-up degradation pattern. Sediments will reach the lower sections of the trench and start building up at the lower end of the HFD, reducing the overall drainage capacity of the filter material. While the first pattern can be currently evaluated by visual means (subjectively at the least), the second manifests well below the surface of the trench and depth-specific assessment (based on intrusive or non-intrusive techniques) is required to assess the expected drop in serviceability levels. Depending on the severity of fouling and extent in the HFD trench, this mode may lead to reduced subsurface and surface water removal capacity. The two modes can be linked in an HFD-explicit ageing model, and this concept is further developed in the following section.
Discreet condition states: defining the boundaries and embedding maintenance activities

With no available quantitative data to represent the deterioration progress of HFD in the highways network, Figure 4 represents a conceptualised definition of six discreet HFD condition bands along with the currently available renewal strategies that restore the condition of the drains from a downstream band (lower drainage capacity), to an upstream condition (higher drainage capacity). The four main states proposed here are excellent condition, fair condition, poor condition and very poor condition with two subcategories representing the top-down failure modes: fair crusted and poor crusted (EC, FC, PC, VPC, FCC and PCC, respectively).

The two crusted condition bands are critical for safety reasons and are introduced here to enable separation of the two identified failure modes through network surveys and previous field studies. Lastly, the very poor condition represents an HFD section that 


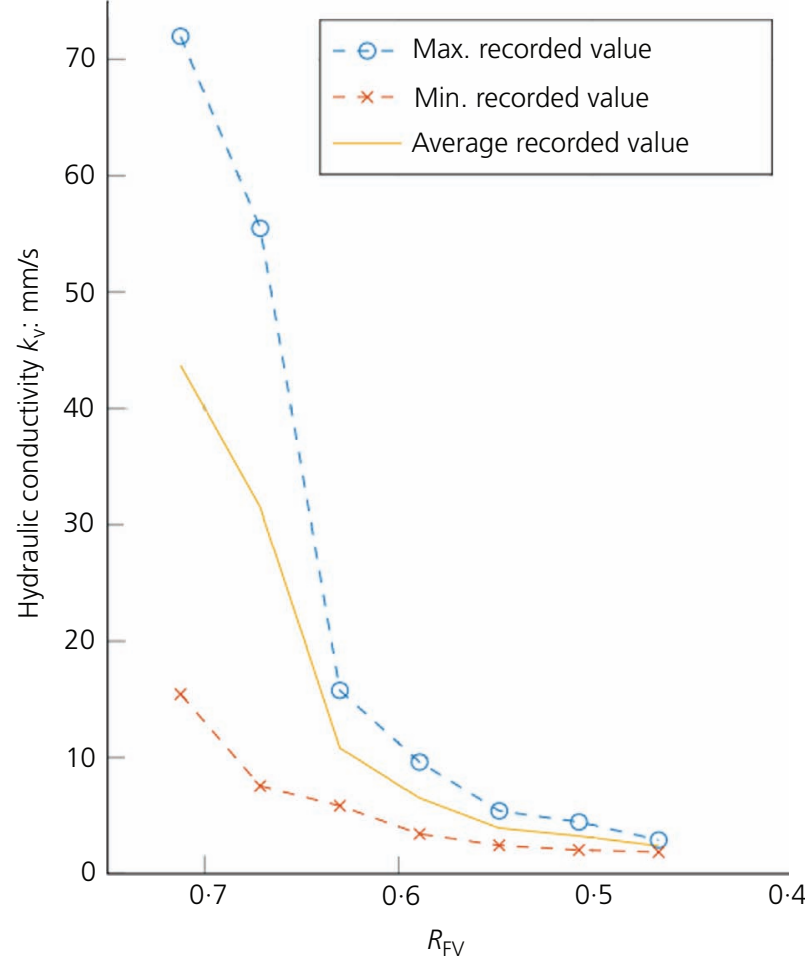

Figure 3. Hydraulic conductivity values as a function of free-voids ratio $\left(R_{\mathrm{FV}}\right)$ for reconstructed samples

has surpassed its projected service life (reduced surface and subsurface drainage capacities) and which presents a foulantdominated aggregate fill. The effect of the various available maintenance options on the overall condition of a section is also visualised in the diagram.
It is crucial to identify and establish for such a concept relevant criteria to form the boundaries between each condition state (linked to the condition assessment regime proposed). The field and laboratory data presented in Stylianides et al. (2015) suggest that a layer-by-layer analysis is required to classify the serviceability levels of the trench and to evaluate the different failure modes. The FC and PC states, for example, are manifested in the uppermost of the drain and can thus be easily identified under a reactive regime; if a more proactive (or on-condition) approach is required (and this paper suggests that this is in fact the case), a quantification of fouling levels (FL) mapped to anticipated drainage capacity should be achieved.

The permeability trials conducted exhibit how $k_{\mathrm{v}}$ as a function of FL can be extracted in a controlled experiment. Being a free draining material (void ratio of type $B$ material measured to range between 0.66 and 0.80 ) with a large void space, a major drop in permeability values (and thus drainage capacity) is expected only when fouling extent reaches significant levels within the trench. A foulant-dominated fill will be one for which the drainage capacity will be a function of the foulant rather than the aggregate fill $\left(k_{\mathrm{v}}<5 \mathrm{~mm} / \mathrm{s}, R_{\mathrm{FV}}<0.6\right)$. Its functionality will thus be hindered and the removal of surface or subsurface water will be reduced. We can thus establish certain boundaries between discreet condition states, and these are presented (in a qualitative manner) in Table 1 linked to anticipated FL.

\section{Deterioration modelling}

Employed with an HFD generic ageing/renewal model, asset owners can assess and characterise filter drain sections within an evaluated network according to quantitative fouling and performance levels. In line with PMS presented in previous

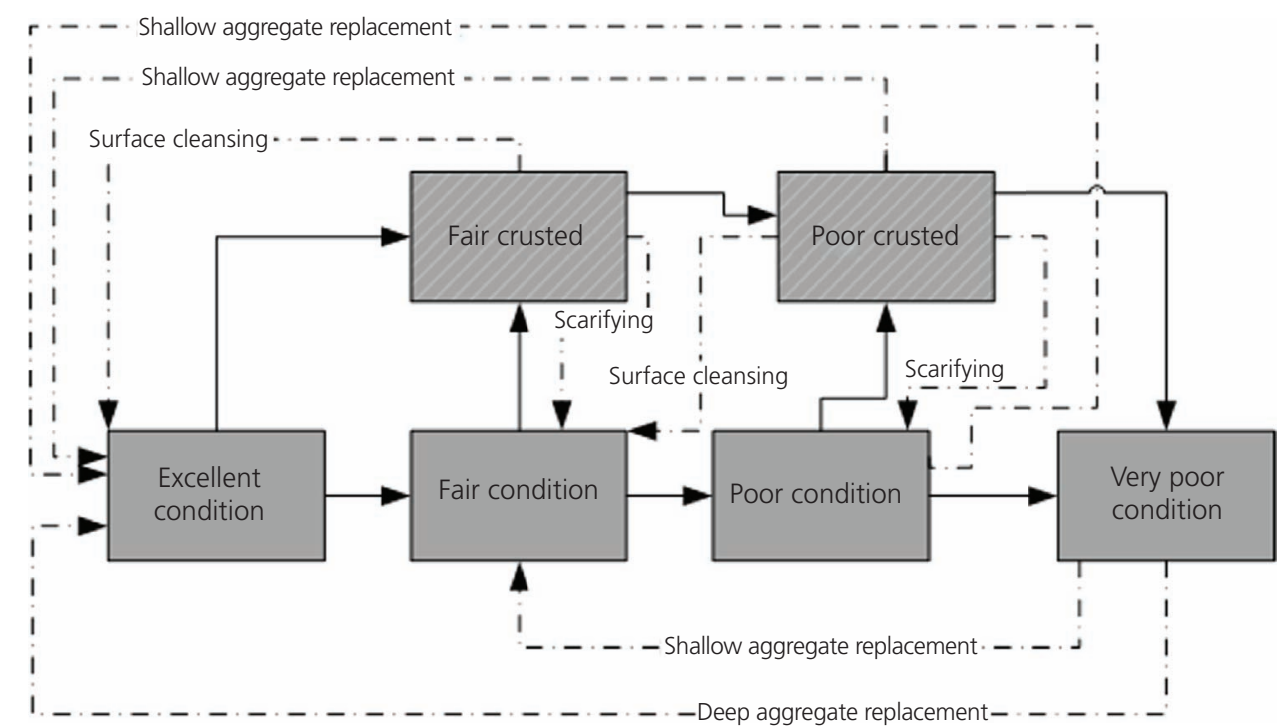

Figure 4. General ageing/renewal model proposed for evaluation of HFD 


\begin{tabular}{|c|c|c|c|c|}
\hline \multirow{2}{*}{$\begin{array}{l}\text { Condition } \\
\text { band }\end{array}$} & \multicolumn{2}{|c|}{ Condition criteria } & \multicolumn{2}{|c|}{ Anticipated performance } \\
\hline & Surface & Subsurface & Surface & Subsurface \\
\hline 1. EC & $\begin{array}{l}\text { Highly porous } \\
\text { (minimal to zero FL) }\end{array}$ & $\begin{array}{l}\text { Highly porous } \\
\text { (minimal to zero FL) }\end{array}$ & Free draining & Free draining \\
\hline 2. FC & $\begin{array}{l}\text { Highly porous } \\
\text { (minimal to moderate FL) }\end{array}$ & $\begin{array}{l}\text { Highly porous } \\
\text { (minimal to moderate } \mathrm{FL} \text { ) }\end{array}$ & $\begin{array}{l}\text { No impact on drainage } \\
\text { performance }\end{array}$ & $\begin{array}{l}\text { No impact on drainage } \\
\text { performance }\end{array}$ \\
\hline 3. FCC & $\begin{array}{l}\text { Reduced porosity } \\
\text { (moderate to high FL) }\end{array}$ & $\begin{array}{l}\text { Highly porous } \\
\text { (minimal to moderate FL) }\end{array}$ & $\begin{array}{l}\text { Reduced water removal } \\
\text { capacity }\end{array}$ & $\begin{array}{l}\text { No impact on drainage } \\
\text { performance }\end{array}$ \\
\hline 4. $P C$ & $\begin{array}{l}\text { Minimal porosity } \\
\text { (high to very high FL) }\end{array}$ & $\begin{array}{l}\text { Minimal porosity } \\
\text { (high to very high FL) }\end{array}$ & $\begin{array}{l}\text { Minimal water removal } \\
\text { capacity }\end{array}$ & $\begin{array}{l}\text { Minimal water removal } \\
\text { capacity }\end{array}$ \\
\hline 5. PCC & Foulant-dominated fill & $\begin{array}{l}\text { Minimal porosity } \\
\text { (high to very high FL) }\end{array}$ & Zero water removal capacity & $\begin{array}{l}\text { Minimal water removal } \\
\text { capacity }\end{array}$ \\
\hline 6. VPC & Foulant-dominated fill & Foulant-dominated fill & Zero water removal capacity & Zero water removal capacity \\
\hline
\end{tabular}

Table 1. HFD discreet condition bands and condition criteria and anticipated drainage performance

sections, to add value to this model, a mathematical representation of ageing and renewal policies should be considered.

In its simplest form, a generalised deterioration/renewal mathematical model conceptualised by De La Garza and Krueger (2007) is depicted in Equation 2. In principle, the model determines the annual change in the asset condition by calculating the effects of maintenance treatments on the various condition levels and then ageing the resulting condition distributions according to the adopted deterioration rates.

$$
\begin{aligned}
& \text { Condition }_{j}(t+1)=\text { Condition }_{j}(t)-\frac{\text { Condition }_{j}(t)}{D_{j k}} \\
& \text { 2. } \quad+\frac{\text { Condition }_{i}(t)}{D_{i j}}+\sum R_{k j}(t)-\sum R_{j i}(t)
\end{aligned}
$$

Deterioration rates (denoted by $D_{i j}$ and $D_{j k}$ ) can be extracted using either probabilistic or deterministic means, while $R_{k j}$ and $R_{j i}$ denote the upstream condition changes due to maintenance interventions (i.e. the impact of maintenance options on condition states). Focusing back to HFD management requirements, the impact of treatment options on condition states ( $R$ values) and a methodology to predict deterioration ( $D$ values) using the proposed condition classification framework (Table 1, Figure 4) should be defined.

An example of such a work in the sector has recently been presented by Costello et al. (2011), which describes a DST for managing ancillary assets using proactive principles. The methodology in this work draws from standard inventory collection practices and adopts five discreet condition bands and probabilistic Markov chains to simulate the deterioration of the assets (and to tackle the absence of historic condition data reported in the work). Once the required data for year one is collected (using a simplified CAS), a base condition vector is established to describe the condition distribution of assets within the network with bands ranging between excellent to very poor. The authors then calculate and present deteriorated states (the ageing process) using a transition probability matrix throughout the planning horizon in a given network. Having no records of deterioration rates, engineering judgement is used and a linear model to set up a life-cycle planning model is defined.

Looking back to HFD deterioration understanding, empirical evidence suggests a larger than 10-year operational life (reported to extend past the 20-year mark in some cases). Similar to the ancillary assets case, the typically reactive HFD management approach falls short in terms of enabling the collection and use of relevant condition information that could be embedded in a deterioration model (and thus allow the extraction of relevant $D$ values as per De La Garza and Krueger, 2007). To enable a network level evaluation of HFD and predict the condition of the drainage network in discreet condition bands, a Markov probabilities transition matrix is proposed to represent ageing in a defined network. The six condition states $(n$-EC, FC, FCC, PC, PCC, VPC) introduced in this work (Table 1) are adopted, and an asset life $(L)$ equal to 25 years is used; lastly, the deterioration is assumed to progress in a linear manner. The calibration and the level of accuracy of such a probability matrix will inevitably be a result of the collection of annual network-level condition data.

Using this scenario and adopting a base condition vector to denote $100 \%$ of the HFD network to lie within the excellent condition band (year 0), the progression of deterioration can be extracted for the whole network using the transition probabilities (extracted using Equations 3a, 3b). This is done by basic matrix manipulation; to extract the first year's deteriorated vector $\left(\boldsymbol{a}_{1}\right)$, one needs to multiply the base condition vector $\left(\boldsymbol{a}_{0}=[1,0,0,0\right.$, 
$0,0])$ with the probability matrix $P$; to calculate the condition distribution at any future year, $\boldsymbol{a}_{t}=\boldsymbol{a}_{t-1} P=\boldsymbol{a}_{0} P^{t}$ can be used.

3a. $\alpha=\frac{n-1}{L}$

$\begin{aligned} P & =\left[\begin{array}{cccc}p_{11} & p_{12} & \cdots & p_{1 n} \\ p_{21} & p_{22} & \cdots & p_{2 n} \\ \vdots & \ddots & \ddots & \vdots \\ p_{n 1} & p_{n 2} & \cdots & p_{n n}\end{array}\right] \\ \text { 3b. } \quad & {\left[\begin{array}{cccccc}1-2 \alpha & \alpha & \alpha & 0 & 0 & 0 \\ 0 & 1-2 \alpha & \alpha & \alpha & 0 & 0 \\ 0 & 0 & 1-\alpha & 0 & \alpha & 0 \\ 0 & 0 & 0 & 1-2 \alpha & \alpha & \alpha \\ 0 & 0 & 0 & 0 & 1-\alpha & \alpha \\ 0 & 0 & 0 & 0 & 0 & 1\end{array}\right] }\end{aligned}$

Adopting the transition probabilities matrix (TPM) and using the parameters described in the previous paragraphs, one can graphically represent the deterioration of HFD in a given network as shown in Figure 5.

\section{Defining a pragmatic HFD DST}

Central to AM systems are asset renewal and replacement analysis methods. These are economic efficiency assessments of the impact of all $M, R \& R$ actions to exhibit the effect of intervention strategies on the asset's future condition (the positive effect of maintenance) mapped against anticipated project costs. This will allow the development of a multiyear HFD maintenance programme for an entire road network.

Figure 5 represents HFD ageing (at the network level) assuming no maintenance interventions during a 30 -year period; it is a graphical representation of how year 0 condition distributions in the network (denoted by the base vector $\boldsymbol{a}_{0}$ ) are projected in a specified planning horizon using the TPM proposed in Equation 3b. When interventions are to be taken into account, a DST is essential to dictate how and when maintenance is triggered, how investment scenarios should be formulated and what strategies are to be selected. By taking current and future condition data into account (assuming the Markov process can be used to model the deterioration process), asset owners adopting a DST will be able to address

What is the cost of to-date deferred maintenance (current maintenance backlog)?

What are the remaining service lives?

- What should be prioritised?

- What is the optimum maintenance strategy to be formulated for a defined planning horizon?

The structure of such a DST can be seen in Figure 6. The tool requires the definition of a clear system objective which can be the maximisation of HFD network performance or minimisation of maintenance costs over a planning horizon. The proposed DST uses such inputs as inventory and condition data, deterioration models and maintenance options impacts and unit rates. By embedding performance targets and constraints (financial or minimum condition based), asset owners and managers will be able to establish rational and targeted maintenance scheduling at first, and eventually, optimal lifecycles and long-term investment planning.

\section{Conclusions}

AM strategies have given rise to sustainable management of transportation assets in recent times. This paper suggests that drainage should be embedded in AM systems (or drainage management should adopt AM thinking) and a rational approach to establish proactive means to manage HFD should be formulated. Current practices tend to ignore the collection of relevant information to enable the use of such an approach, and focus instead on reactive or risk-based philosophies that often translate to incurred costs to both road operators and road users.

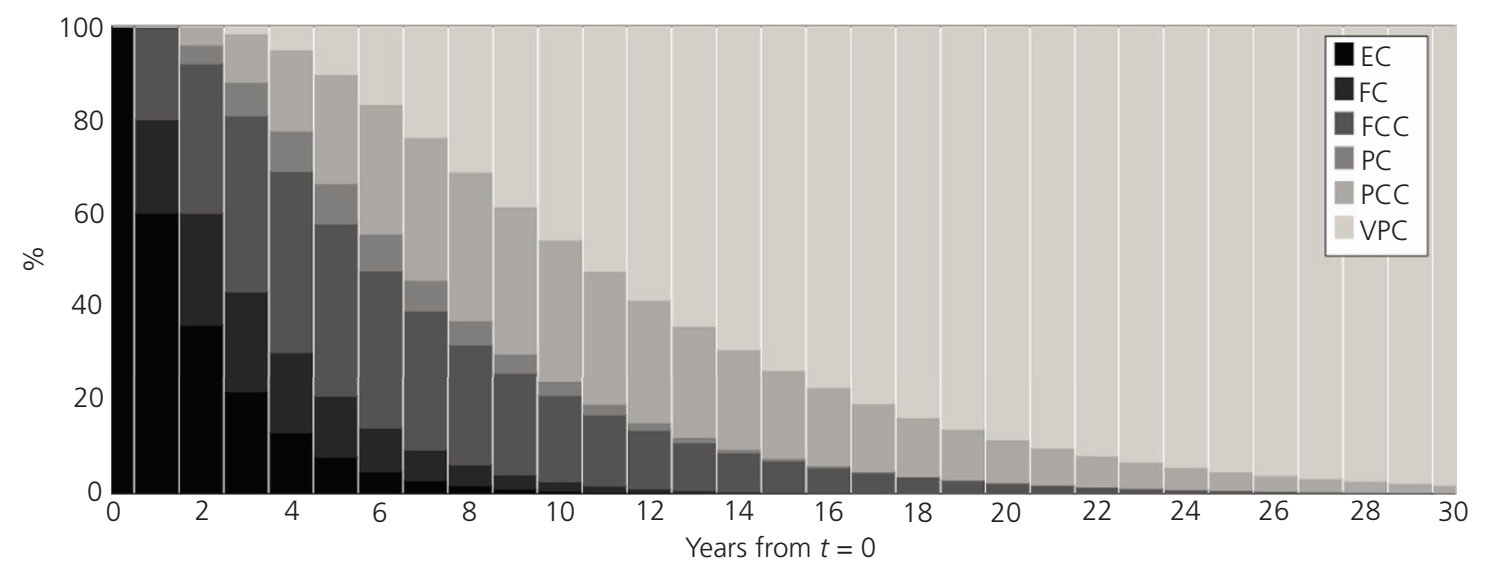

Figure 5. Distribution of HFD network condition bands adopting $L=25$ and linear deterioration progression; $a_{0}=[1,0,0,0,0,0]$ 


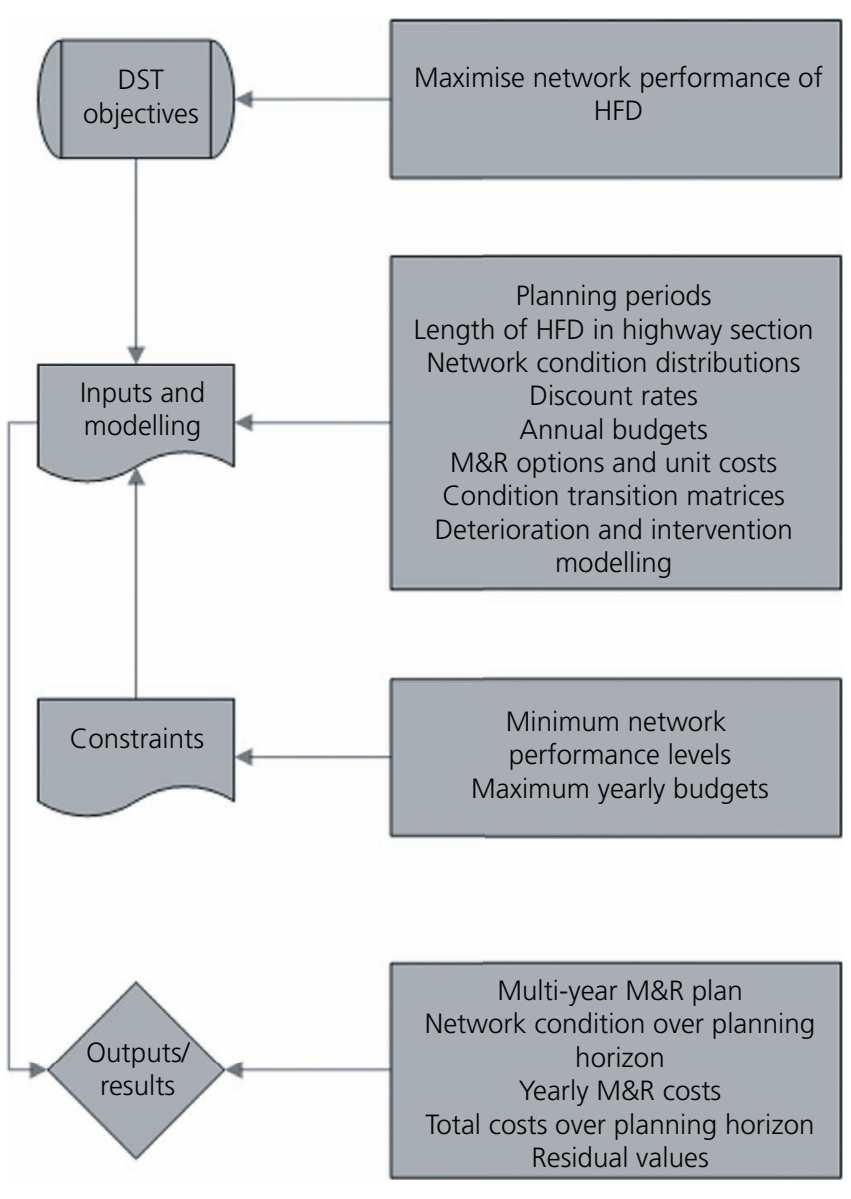

Figure 6. DST structure adopted by Wong et al. (2003) and modified for HFD MS

Existing maintenance thinking and AM strategies have been evaluated through available guides and relevant publications, and the need to address a number of HFD-specific issues has been identified. The fact that strategic AM documents introduce only the fundamental concepts to be developed and drainage-related literature is limited and insufficient to support the prerequisites for holistic management suggest the need to address the following questions

- What kind of HFD data are to be collected?

- How are these to be used?

- In what sense will the outputs reinforce the case of AM and be of true value?

The paper has focused on conceptualising the engineering end of $\mathrm{AM}$ by introducing HFD condition metrics and tools to project ageing and deterioration (using a Markov TPM) and a DST framework that could enable road engineers to monitor life-cycle costs by embedding the aforementioned management elements.

By defining two distinctive HFD failure modes and the resulting functional impairment, a general ageing/renewal model has been conceptualised. Mapped to a deterioration mathematical model, six discreet condition bands to represent the ageing of the asset have been introduced. Looking at the limited field evaluations and the existing historical data available (primarily empirical network understanding), it is proposed that current projections of HFD service lives underestimate the capacity of the asset to operate at acceptable service levels.

While based on engineering judgement and limited field and laboratory evaluations, a rational (and network specific) approach to classify the performance of the asset is proposed (also recognising the need to separate the surface and subsurface functions of the drain). The condition and performance information to be collected should provide the quantitative basis for informed maintenance planning; this thinking can address the need to assess the physical condition, level of service and the effect of proposed treatment options of HFD in a specified planning horizon, while focusing on easily attainable and processed management data.

\section{Further work}

To introduce an HFD management platform, a number of filterdrain-specific parameters have been conceptualised and introduced in this paper. While variables and condition metrics to establish a CAS have been presented, the embedded methodology assumes an intrusive approach that factorises fouling levels and rational quantification of sedimentation in HFD trenches.

Central to this research is the development of a network level, non-intrusive assessment approach, which ties the relevant condition concepts with performance and drainability levels (while the measurement of water flows within specific HFD sections as a direct measurement of drainage capacity could form the basis for direct extraction of performance levels). An objective of the work is thus the integration of ground-penetrating radar surveys within a CAS and the extraction of relevant condition information for HFD. This will enable a network level evaluation and the collection of relevant condition data to implement and optimise the required deterioration modelling and DST. Relevant trials are hence currently being undertaken in collaboration with the industrial partner, pavement testing services (PTS), and the evaluation of HFD shows promising results.

Further hydraulic trials and quantification of permeability values will also enable and validate the comparison of the various condition bands introduced. The concept of sedimentation and reduced drainage capacity is clearly well understood in the industry. The requirement is the establishment of rational engineered indices that classify drainage performance and allow asset owners and operators to target maintenance interventions according to needs and life-cycle projections.

\section{Acknowledgements}

The research work described in this paper has been funded by the Engineering and Physical Sciences Research Council (EPSRC), Transport Scotland (TS), Connect Roads, Balfour Beatty and PTS. The opinions and findings are those of the authors and do not necessarily represent the views of TS. 


\section{REFERENCES}

Abaza KA (2004) Deterministic performance prediction model for rehabilitation and management of flexible pavement. International Journal of Pavement Engineering 5(2): 111-121.

Abaza Z, Ashur S, Abu-Eisheh S and Rabay AA (2001) Macroscopic optimum system for management of pavement rehabilitation. Journal of Transportation Engineering 127(6): 493-500.

Abaza KA, Ashur S and Al-Khatib I (2004) Integrated pavement management system with a Markovian prediction model. Journal of Transportation Engineering 130(1): 24-33.

Ahmad R and Kamaruddin S (2012) An overview of time-based and condition based maintenance in industrial applications. Computers and \& Industrial Engineering 63(1): 135-149.

Al-Qadi I, Xie W and Roberts R (2008) Scattering analysis of ground penetrating radar data to quantify railroad ballast contamination. NDT\&E International 41(6): 441-447.

Anbazhagan P, Lijun S, Buddhima I and Cholachat R (2011) Model track studies on fouled ballast using ground penetrating radar and multichannel analysis of surface wave. Journal of Applied Geophysics 74(4): 175-184.

Anbazhagan P, Bharatha TP and Amarajeevi G (2012) Study of ballast fouling in railway track formations. Indian Geotechnical Journal 42(2): 87-99.

Bournemouth Borough Council (2008) Highway Asset Management Plan. UK.

BSI (British Standards Institute) (2014) ISO 55000:2014 Asset management. BSI, London, UK.

Cambridge Systematics, Texas Transportation Institute, National Cooperative Highway Research Program, American Association of State Highway and Transportation Officials, \& Parsons Brinckerhoff (2006) Performance Measures and Targets for Transportation Asset Management. Transportation Research Board, Washington, DC, USA.

Cedergren HR (1974) Drainage of Highway and Airfield Pavements. Krieger Publishing, Malabar, FL, USA.

Costello SB, Moss WF, Read CJ and Grayer S (2011) Life-cycle planning methodology for ancillary highway assets. Proceedings of the Institution of Civil Engineers - Transport 164(4): 251-257.

De La Garza JM and Krueger D (2007) Simulation of highway renewal asset management strategies. In Computing in Civil Engineering (Soibelman L and Akinci B (eds)). American Society of Civil Engineers, Reston, VA, USA, pp. 527-541. DFT (Department for Transport) (2014) Action for Roads - A Network for the 21st Century. The Stationery Office, London, UK.

Dornan DL (2002) Asset management: remedy for addressing the fiscal challenges facing highway infrastructure. International Journal of of Transport Management 1(1): 41-54.

Farrar D (1994) Review of transport research laboratory research on highway drainage. Quarterly Journal of Engineering Geology and Hydrogeology 27(4): 309-318.

Farrar D and Samuel H (1989) Field Study of Filter Drains at Swanley, Kent. Transport and Road Research Laboratory, Wokingham, Berkshire, UK.
Feldman N and Nissen D (2002) Alternative Testing Method for the Measurement of Ballast Fouling: Percentage Void Contamination. Conference on Railway Engineering, Australia.

Godau RI (1999) The changing face of infrastructure management. Systems Engineering 2(4): 226-236.

Golabi K, Kulkarni RB and Way GB (1982) A statewide pavement management system. Interfaces 12(6): 5-21.

Haas R, Hudson WR and Zaniewski JP (1994) Modern pavement management. Krieger Publishing. Malabar, FL, USA.

Hassanain MA, Froese FM and Vanier DJ (2003) Framework model for asset maintenance management. Journal of Performance of Constructed Facilities 17(1): 51-64.

Highways Agency (1998) DMRB, Volume 4, Section II: Edge of Pavement details. The Stationery Office, London, UK.

HMEP (Highways Maintenance Efficiency Programme) (2012) Guidance on the Management of Highway Drainage Assets. Department for Transport, London, UK.

Hudson WR, Finn FN, McCulluogh BF, Nair K and Vallerga BA (1968) Systems Approach to Pavement Design: System Formulation, Performance Definition and Material Characterization. Materials Research and Development, Inc., Oakland, CA, USA.

Johnson FL and Chang FFM (1984) Drainage of Highway Pavements. US Department of Transportation, Washington, DC, USA.

Klutke GA, Kiessler PC and Wortman M (2003) A critical look at the bathtub curve. IEEE Transactions on Reliability 52(1): 125-129.

Leng Z and Al-Qadi I (2009) Dielectric constant measurement of railroad ballast and application of STFT for GPR data analysis. NDTCE'09, Non-Destructive Testing in Civil Engineering, Nantes, France, 30 June-3 July.

Li Z and Sinha KC (2004) Multicriteria Highway Programming Incorporating Risk and Uncertainty: A Methodology for Highway Asset Management System. PhD dissertation, Purdue University, West Lafayette, IN, USA.

Li Z, Haas R and Xie WC (1997) Development of new asphalt pavement performance prediction model. Canadian Journal for Civil Engineering 24(4): 547-559.

Mallic RB and El-Korchi T (2013) Pavement Engineering: Principles and Practice. CRC Press, Boca Raton, FL, USA.

Markow MJ (1995) Highway management systems: state of the art. Journal of Infrastructure Systems 1(3): 186-191.

Middlesbrough Council (2006) Highways Maintenance Plan. Environment Department Transport and Design Services, Middlesbrough, UK.

PAS (Publicly Available Standards) (2008) PAS 55-1:2008: Specification for the Optimized Management of Physical Assets. BSI, London, UK.

Robinson R, Danielson U and Snaith M (1998) Road Maintenance Management - Concepts and Systems. Palgrave Macmillan, Basingstoke, UK. 
Rowlands G and Ellis JB (2007) Highway filter drain maintenance and re-instatement: a waste management issue. Sixth International Conference on Sustainable Techniques and Strategies in Urban Water Management, Lyon, France, pp. 1173-1180.

Samuel H and Farrar D (1988) Field Study of Filter Drains on Maidstone by-pass, Kent. Transport and Road Research Laboratory, Wokingham, Berkshire, UK.

Selig ET and Waters JM (1994) Track Geotechnology and Substructure Management. Thomas Telford, London, UK.

Spink T, Duncan I, Todd A and Lawrance A (2014) Transport Infrastructure Drainage: Condition Appraisal and Remedial Action. CIRIA, London, UK.

Stylianides T, Frost MW, Flemming PR, El-Jaber A and Mageean $M$ (2015) Assessment of highway filter drain fouling and performance considerations. Transportation Research Board 94th Annual Meeting, 11-15 January, Washington, DC. TRB, Washington, DC, USA.

Suffolk County Council (2008) Highway Maintenance Operational Plan. Ipswich, Suffolk, UK.

Sussman TR, Ebershn W and Selig ET (2001) Fundamental nonlinear track load-deflection behavior for condition evaluation. Transportation Research Record 1742: 61-67.

Sussman TR, Ruel M and Chrismer SM (2012) Source of ballast fouling and influence considerations for condition assessment criteria. Transportation Research Record 2289: 87-94.

Swanson L (2001) Linking maintenance strategies to performance. International Journal of Production Economics 70(3): 237-244.
Taggart A, Tachtsi L, Lugg M and Davies H (2014) UKRLG framework for highway infrastructure asset management. Infrastructure Asset Management 1(1): 10-19.

Takata S, Kirnura F, Van Houten FJM et al. (2004) Maintenance: changing role in life cycle management. CIRP Annals Manufacturing Technology 53(2): 643-655.

Tenakoon N, Buddhima I, Cholachat R, Nimbalkar S and Neville T (2012) The role of ballast fouling characteristics on the drainage capacity of rail substructure. Geotechnical Testing Journal 35(4): 1-4.

Uddin W, Hudson W and Haas R (2013) Public Infrastructure Asset Management. McGraw Hill Professional, New York, NY, USA.

UK Roads Board (2005) Well Maintained Highways - Code of Practise for Highway Maintenance Management. The Stationery Office, London, UK.

UKRLG (UK Roads Liaison Group) (2013) Highway Infrastructure Asset Management. The Stationery Office, London, UK.

Walsall Council (2012) Highway Asset Management Plan. Walsall, West Midlands, UK.

Wittwer E, Bittner J and Switzer A (2002) The fourth national transportation asset management workshop. International Journal of of Transport Management 1(2): 87-99.

Wong W, He G and Luk S (2003) Development of road management systems in China. Proceedings of the Institution of Civil Engineers - Transport 156(4): 179-188.

Yam RCM, Tse PW, Li L and Tu P (2001) Intelligent predictive decision support system for condition-based maintenance. The International Journal of Advanced Manufacturing Technology 17(5): 383-391.

\section{WHAT DO YOU THINK?}

To discuss this paper, please submit up to 500 words to the editor at journals@ice.org.uk. Your contribution will be forwarded to the author(s) for a reply and, if considered appropriate by the editorial panel, will be published as a discussion in a future issue of the journal. 